\title{
Epigenetic Interactions and the Structure of Phenotypic Variation in the Cranium
}

\section{Citation}

Hallgrimssona, B., Daniel E. Liebermanb, W. Liua, A.F. Ford-Hutchinson, and F.R. Jirik. 2007. Epigenetic interactions and the structure of phenotypic variation in the cranium. Evolution and Development 9(1): 76-91.

\section{Published Version}

http://dx.doi.org/10.1111/j.1525-142X.2006.00139.x;doi:10.1111/j.1525-142X.2006.00139.x

\section{Permanent link}

http://nrs.harvard.edu/urn-3:HUL.InstRepos:3716667

\section{Terms of Use}

This article was downloaded from Harvard University's DASH repository, and is made available under the terms and conditions applicable to Other Posted Material, as set forth at http:// nrs.harvard.edu/urn-3:HUL.InstRepos:dash.current.terms-of-use\#LAA

\section{Share Your Story}

The Harvard community has made this article openly available.

Please share how this access benefits you. Submit a story.

Accessibility 


\title{
Epigenetic interactions and the structure of phenotypic variation in the cranium
}

\author{
B. Hallgrímssona,*,1, D.E. Liebermanb,1, W. Liua, A.F. Ford-Hutchinsonc, and F.R. Jirikc \\ aDepartment of Cell Biology and Anatomy, Alberta Bone and Joint Institute, Faculty of Medicine, University of Calgary, \\ 3330 Hospital Dr. NW, Calgary, AB, Canada T2N 4N1 \\ bepartments of Anthropology and Organismic and Evolutionary Biology, Harvard University, 11 Divinity Avenue, Cambridge, \\ MA 02138, USA \\ ${ }^{\mathrm{C} D e p a r t m e n t}$ of Biochemistry and Molecular Biology, Alberta Bone and Joint Institute, Faculty of Medicine, University of \\ Calgary, 3330 Hospital Dr. NW, Calgary, AB, Canada T2N 4N1 \\ *Author for correspondence (email: bhallgri@ucalgary.ca) \\ ${ }^{1}$ These authors contributed equally to this work.
}

SUMMARY Understanding the developmental and genetic basis for evolutionarily significant morphological variation in complex phenotypes such as the mammalian skull is a challenge because of the sheer complexity of the factors involved. We hypothesize that even in this complex system, the expression of phenotypic variation is structured by the interaction of a few key developmental processes. To test this hypothesis, we created a highly variable sample of crania using four mouse mutants and their wild-type controls from similar genetic backgrounds with developmental perturbations to particular cranial regions. Using geometric morphometric methods we compared patterns of size, shape, and integration in the sample within and between the basicranium, neurocranium, and face. The results highlight regular and predictable patterns of covariation among regions of the skull that presumably reflect the epigenetic influences of the genetic perturbations in the sample. Covariation between relative widths of adjoining regions is the most dominant factor, but there are other significant axes of covariation such as the relationship between neurocranial size and basicranial flexion. Although there are other sources of variation related to developmental perturbations not analyzed in this study, the patterns of covariation created by the epigenetic interactions evident in this sample may underlie larger scale evolutionary patterns in mammalian craniofacial form.

\section{INTRODUCTION}

In order to test hypotheses about evolutionary changes in phenotype, it is often necessary to understand their underlying genotypic and developmental bases. This is a challenge because complex phenotypes arise from many sequential interactions among genes, cells, tissues, organs and the environment. Yet, in spite of this complexity, simple modifications to developmental pathways may often generate novel adaptive phenotypes by using basic "toolkit" genes that function in diverse developmental contexts (Atchley and Hall 1991; Davidson et al. 2002; Wilkins 2002; Carroll et al. 2005). Such tinkering permits evolvability, but also leads to integration, as manifested through covariation among structures. It follows that mutations that produce evolutionarily significant variation can generate seemingly unrelated suites of integrated phenotypic change that may obfuscate where selection acted (e.g., Kangas et al. 2004).

Here, we focus on the problem of how modifications to complex developmental pathways cause integrated phenotyp- ic change in the skull. The skull is arguably the most complexly integrated region of the skeleton because it comprises many closely packed capsules surrounding organs and spaces such as the brain and the pharynx, in which most bony walls are shared between capsules (Moss and Young 1960; Enlow 1990; Moss 1997a,b,c,d). In addition, the skull performs many dynamic functions, some of which involve substantial mechanical forces that affect multiple regions. These functions are maintained as the skull changes enormously in size and shape during ontogeny. Without multiple mechanisms of integration, such a complex structure would probably fail to grow and function correctly, and evolve. Finally, the skull has been the locus of many key evolutionary transformations, including changes associated with the origins of our own species, Homo sapiens (Lieberman et al. 2002).

The skull's complexity poses many challenges for understanding its evolutionary developmental bases. However, there may be some simplifying principles. The skull comprises three partially independent and embryologically distinct units that surround a few dominant organs and spaces 


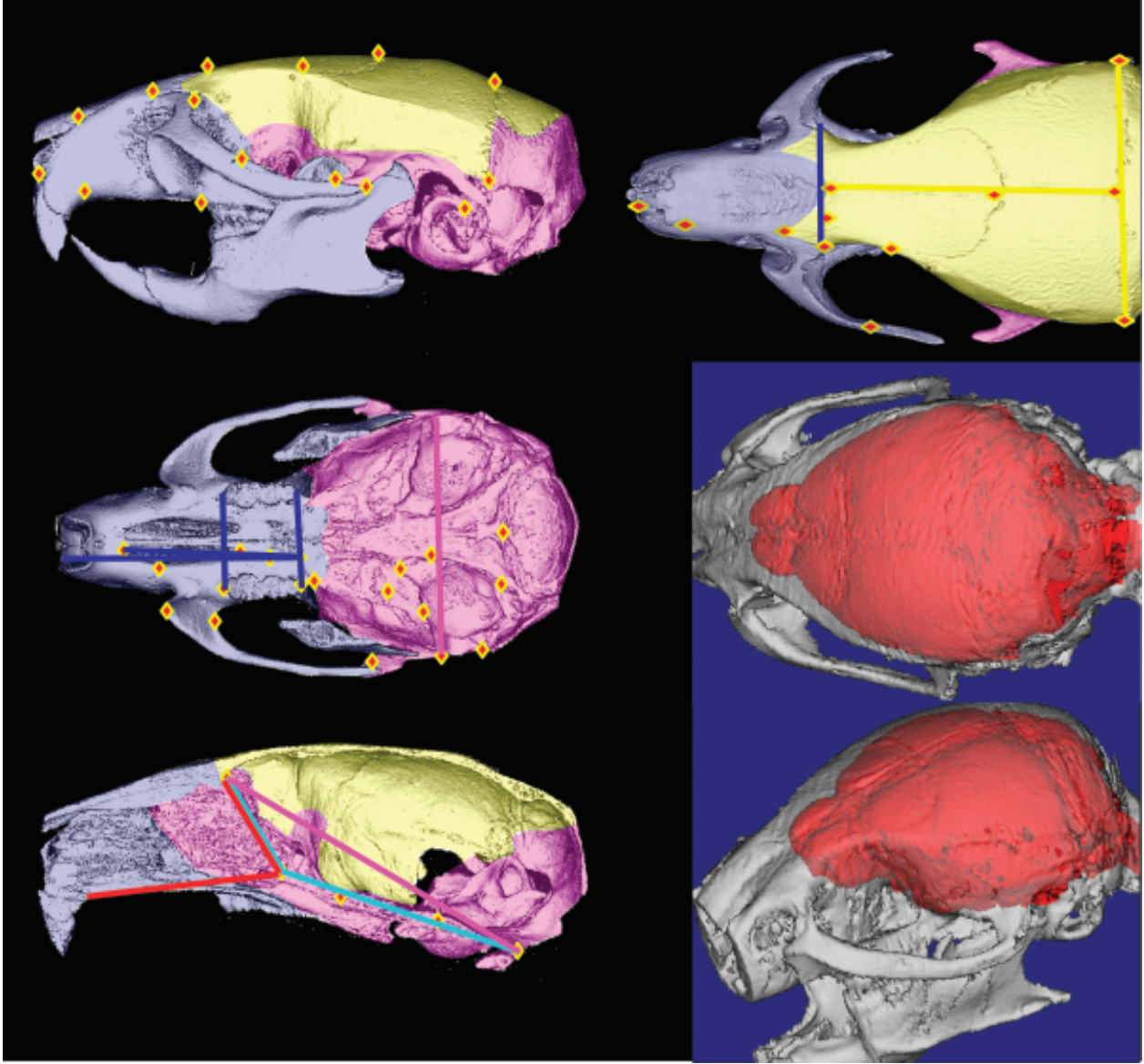

Fig. 1. Developmental modules in the mammalian skull shown in a C57BL/6J mouse. THREE-dimensional landmarks and a priori variables used in this study are also shown. The interlandmark distances used for facial length and width are shown in dark blue, those used for neurocranial length and width in yellow and basicranial length and width in violet. The light blue and red angles show the basicranial and facial angles. A virtual endocranial cast used to calculate endocranial volume is shown in red. Human skull modified with permission after Rohan et al. (1988).
(Fig. 1): the basicranium (derived from the chondrocranium), the neurocranium (the dermatocranial bones of the cranial vault), and the face (derived initially from the splanchnocranium with subsequent development of dermatocranial elements). These regions behave as modules by varying somewhat independently (Cheverud 1982b, 1989, 1995; Lieberman et al. 2000b; Hallgrímsson et al. 2004b). In addition, these modules may interact unequally via epigenetic interactions (we use the term epigenetic in a general sense to refer to interactions between a given cell and its environment, including other cells, that influences the cells activity).

There are several reasons to hypothesize that the basicranium acts as the skull's central integrator (De Beer 1937; Lieberman et al. 2000a). First, the basicranium is located in the center of the skull, below the brain and neurocranium but above and behind the face. Thus, variation is transmitted between the face and neurocranium indirectly via the basicranium. In addition, the basicranium is the first part of the cranium to attain adult size and shape, slightly before the neurocranium, and long before the face (Stamrud 1959; Moore and Lavelle 1974; Baughan et al. 1979; Farkas et al. 1992). Second, the basicranium grows mostly via endo- chondral ossification in synchondroses (the spheno-occipital, mid-sphenoidal, and spheno-ethmoid). The face and neurocranium, by contrast, grow via intramembranous ossification in sutures. This distinction is relevant because endochondral ossification may be less subject to epigenetic interactions with nearby organs than intramembranous ossification. Intramembranous ossification in the neurocranium and face is driven almost completely by organ growth within capsules in which mechanical forces upregulate transcription factors in sutures to induce osteogenesis (e.g., Opperman 2000; Wilkie and Morriss-Kay 2001; Yu et al. 2001; Spector et al. 2002), but synchondroses elongate much like endochondral growth plates elsewhere in the skeleton. Evidence that synchondroses have some intrinsic growth potential comes from craniofacial syndromes in which abnormal endochondral growth processes cause relatively shortened cranial bases (Cohen et al. 1985; Kreiborg et al. 1993). However, growth of the face and brain also influence endochondral growth in the cranial base (Biegert 1963; Enlow 1990; Lieberman and McCarthy 1999), leading to speculation that variations in neural and facial growth are major influences on craniofacial shape, especially in large 
brained, short-faced creatures such as humans (Weidenreich 1941).

Given the evidence for modularity and integration in the skull, we set out to test experimentally how cranial integration patterns the effects of genetic variation. The question we ask is how and to what extent does variation in one region of the cranium influence variation in size and shape elsewhere? We test two alternative null hypotheses. The first, $\mathrm{H}_{\mathrm{N} 1}$, is that mutations that influence morphogenesis of a particular region will have only localized effects, with little effect on other regions of the cranium. This null hypothesis is expected if the cranium is highly modular and independent. An alternative null hypothesis, $\mathrm{H}_{\mathrm{N} 2}$, is that changes that directly affect the morphogenesis of a particular region will have widespread effects on other regions of the cranium. Such a result would be expected if craniofacial shape derives from multiple distributed interactions.

Finally, we test several alternative hypotheses based on the suggestion that some regions, notably the basicranium, have greater effects on craniofacial shape than others via particular, asymmetrical interactions (i.e., more localized effects in contrast with widespread effects above). The first $\left(\mathrm{H}_{\mathrm{A}}\right)$ is that the basicranium acts as a central integrator of overall craniofacial shape. This could be true because of the cranial base's supposedly intrinsic growth potential, because of its central position between the face and cranial base, or because it finishes growing before the neurocranium and face. Alternative hypotheses are that the brain plays a dominant role in craniofacial shape because of its size and rapid, early growth $\left(\mathrm{H}_{\mathrm{B}}\right)$ and/or that the face has strong effects on craniofacial shape because it has the longest growth period $\left(\mathrm{H}_{\mathrm{C}}\right)$. Each of these hypotheses is schematically represented in Fig. 2.

\section{MATERIALS AND METHODS}

\section{Sample}

To control for age and strain, we composed a sample of four mutant strains as well as wild-type strains of adult mice ( $>90$ days) from similar genetic backgrounds $(\mathrm{C} 57 \mathrm{BL} / 6 \mathrm{~J})$. Each of the mutations included causes perturbations that predominantly influence the basicranium, neurocranium or face.

- Brachymorph (bm) mutants (C57BL/6J background, the Jackson Laboratory, Bar Harbor, ME, USA) have a short cranial base from an autosomal recessive mutation in the phosphoadenosine-phosphosulfate synthetase 2 gene (Papps2) that reduces chondrocranial growth via undersulfation of glycosaminoglycans in cartilage matrix (Kurima et al. 1998; ul Haque et al. 1998).
Hypothesis A

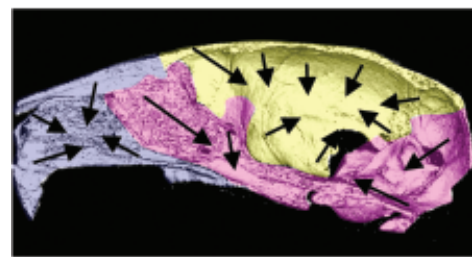

Variation is integrated mainly within modules

Hypothesis C1

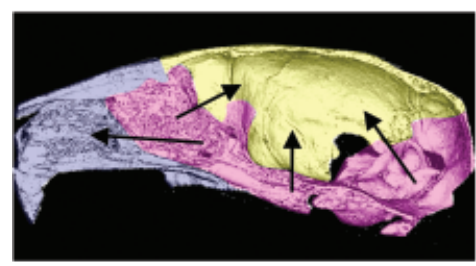

Variation is structured by the growth of the chondrocranium.

\section{Hypothesis B}

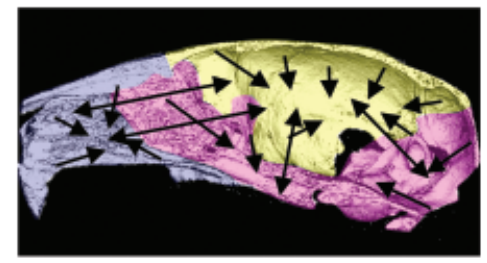

Integration is ubiquitous and unstructured.

Hypothesis C2

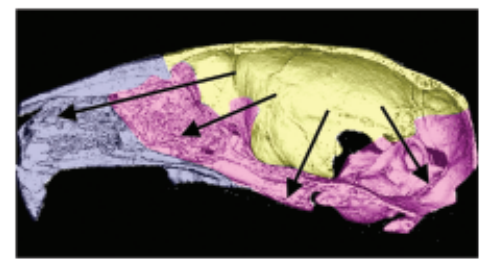

Variation is structured by the growth of the brain.
Hypothesis C3

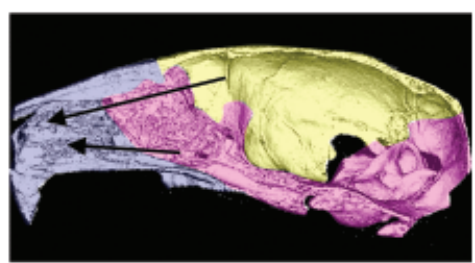

Facial variation is structured by the brain and basicranium.

Fig. 2. Hypothesized patterns of interaction among the cranial modules. Hypotheses A and B show the two alternative null hypotheses. A shows a completely modular organization based on these three regions while B shows integration that is not structured by developmental influences that are particular to these three regions. Hypotheses $\mathrm{C} 1-3$ show the alternatives considered in this paper. In $\mathrm{C} 1$ the basicranium is hypothesized to dominate craniofacial integration because it is the only part of the skull to grow endochondrally, and/or because much of it lies between the face and neurocranium. In $\mathrm{C} 2$, the brain is hypothesized to have dominant effects on integration because of its disproportionate size and/or its early and rapid development. In C3, the face is hypothesized to have dominant effects on integration because of its more extended skeletal growth trajectory. 
- Mice with floxed Pten (tumor-suppressor phosphatase with tensin homology) alleles ( $\sim 90 \%$ C57BL/6J background), provided by T. W. Mak (Ontario Cancer Institute, ON, Canada), were crossed with transgenic mice (on a C57BL/6J background) expressing Cre recombinase under control of the relatively cartilage-specific Col2al gene promoter (Ovchinnikov et al. 2000; obtained from the Jackson Laboratory). As Pten negatively regulates the phosphatidylinositol $3^{\prime}$ kinase signaling pathway that is responsible for controlling cell proliferation and size as well as differentiation and survival (Sansal and Sellers 2004), Pten ${ }^{\text {flox/flox }} \times$ Col2al-Cre mice exhibit increased endochondral bone growth.

- Homozygous mceph (megencephaly) mutants (mixed C57BL/ $6 \mathrm{~J} *$ Balbc/ByJ background, the Jackson Laboratory) have 25\% expanded but normally shaped brains from generalized neural cell hypertrophy generated by a single recessive autosomal mutation, an 11 bp deletion in the Kcnal gene (Diez et al. 2003; Petersson et al. 2003). Individuals were genotyped by PCR (primers: TTG TGT CGG TCA TGG TCA TC [forward], GCC CAG GGT AAT GAA ATA AGG [reverse]), and gel bands were sequenced for a subsample due to the small difference between fragment lengths.

- Homozygous Crf4 mutants (C57BL/6J background, Baylor Mouse Mutant Resource, Baylor College of Medicine, Houston, TX, USA) have $10 \%$ shorter faces than wild types from an autosomal recessive $\mathrm{Crf} 4$ mutation on chromosome 13 that was generated through a $N$-ethyl-N-nitrosourea screen (Kile et al. 2003). The mechanism by which this mutation shortens the face is unknown, but no additional craniofacial abnormalities were reported at screening.

\section{Research design}

The hypotheses tested in this study specify patterns of epigenetic interactions among craniofacial components. Thus, we are interested in how variation in the size of the brain affects the shape of the face, or a change in the size of the chondrocranium affects the shape of the neurocranium and so forth. The independent variables are therefore phenotypic measures like brain size or chondrocranial size that vary both within and among the genotypes analyzed in this study. The mutations used in composing the sample are intended to generate variation in the phenotypic variables of interest, but the hypotheses tested are about patterns of covariation among phenotypic variables. The appropriate unit of analysis for testing these hypotheses, therefore, is the individual and not the genotype. An important assumption made by the among-individual level of analysis, therefore, is that the genetic perturbations act directly only on one of the three regions and that the effects of the mutation on other regions is epigenetic. This assumption is well supported for the bm, Pten, and mceph mutants but much less so for the crf4 mice. The implications of the partial violation of this assumption for interpreting the results are addressed in the discussion. In this design, the covariation structure present in the analyzed sample is determined by the deliberate choice of mutations.

A related set of questions can be asked about covariation at the among-genotype level. For such hypotheses, the developmental effects produced by the genetic perturbations are the independent variables and the unit of analysis is the genotype and not the individual. To address the hypothesis that genetic perturbations that increase brain size all have similar effects on basicranial or facial morphology, for instance, the research design would have to include multiple genetic perturbations that influence brain size. This study is not designed to test hypotheses about among-genotype covariation structure and a study, which does this is planned. However, we did obtain and present below the among-genotype correlations for the major axes of covariation found in this study even though the number of mutations used in this sample is too small for that level of analysis.

\section{Measurements and statistical analysis}

All crania were micro CT-scanned (Scanco Viva-CT40, Scanco Medical AG, Basserdorf, Switzerland) at $35-\mu \mathrm{m}$ resolution $(70 \mathrm{kv}$, $160 \mu \mathrm{A}, 500$ projections). Forty-one three-dimensional (3D) landmarks, shown in Fig. 1, were digitized using Analyze 3D (http:// www.mayo.edu/bir/) with measurement error variances under $1.2 \%$ for interlandmark distances (Hallgrímsson et al. 2004a, b, 2006). Landmarks were assigned to one of the three regions.

We measured regional size and shape variation in two ways. First, we defined a set of a priori variables (APVs, see Table 1) hypothesized to be determinants of craniofacial shape (Enlow 1990; Lieberman et al. 2000b). These include dimensions (maximum width, length, and centroid size) of each region, the angle of the cranial base, and the sphericity of the braincase and endocranial volume. Centroid size is defined as the square root of the summed distances between the centroid (mean $x, y, z$, landmark for the configuration) and each landmark coordinate. Sphericity is measured as the variance of the distance of the neurocranial landmarks to the centroid. These data were transformed in order to equalize the dimensionality of all variables and uncouple the variances from the means. Thus, we use the cube root of endocranial volume and log-transformed all linear distance based variables. Dimensionless variables such as angles and sphericity were not transformed. To remove correlations between these variables due to cranial size, we regressed all variables except the angles and sphericity on cranial centroid size and performed the subsequent analysis entirely on the residuals of those regressions. All measurements in the analysis such as widths, lengths, and centroid sizes are thus relative to cranial size.

Second, we calculated principal components (PCs) of shape variation separately for the basicranium, face and neurocranium (Fig. 1). For each region, a separate Procrustes superimpositions of the raw regional 3D landmarks was performed. The Procrustes procedure removes scale but not the allometric shape variation that is related to size. To remove correlations among shape variables due to allometry, we calculated the residuals of the regional Procrustes coordinates on centroid size and standardized each regional dataset to the mean centroid size for the entire group in ThreeDStand6 (Sheets 2004c). PC variables (PCVs) were thus obtained after removal of the allometric component of shape variation. We used only PCs that accounted for more than $10 \%$ of the variance as PCVs. The PCVs are statistically independent of each other and of size within a given region. Thus, both size and shape variation related to size is removed from both the PCVs before the analysis of covariation structure. 
Table 1. Definitions of a priori variables (APVs)

\begin{tabular}{|c|c|}
\hline Variable & Description \\
\hline Basicranial angle & The angle formed at the sphenoethmoidal synchondrosis between the foramen caecum and basion at the midline \\
\hline Basicranial length & The distance between basion and the foramen caecum \\
\hline Basicranial width & The bilateral distance between external tympanic rings \\
\hline Basicranial size & Centroid size of all basicranial landmarks \\
\hline Neurocranial length & The distance between nasion and lambda \\
\hline Neurocranial width & The bilateral distance between asteria \\
\hline Endocranial volume & Virtual endocast of the cranial vault (measured in Analyze 3D) \\
\hline Neurocranial size & Centroid size of all neurocranial landmarks \\
\hline Sphericity & The variance of the distances from cranial vault landmarks to the centroid \\
\hline Facial angle & $\begin{array}{l}\text { The angle formed at the sphenoethmoidal synchondrosis between the forament caecum and the midline } \\
\text { average of the anterior margins of the incisive foramina }\end{array}$ \\
\hline Facial width & $\begin{array}{l}\text { The average of the palatal widths at the anterior and posterior margins of the molar rows and the widths } \\
\text { between the anterior margins of the frontal bone on the orbit }\end{array}$ \\
\hline Facial length & $\begin{array}{l}\text { The average of palatal lengths from the posterior margins of the palatal process of the palatine bones to the anterior } \\
\text { margins of the incisive foramina and the mid-anterior surface of the upper incisor at the alveolar margin }\end{array}$ \\
\hline Facial size & Centroid size of all facial landmarks \\
\hline
\end{tabular}

APVs and PCVs were compared among groups by ANOVA with Bonferroni's post-hoc comparisons between groups. We used both the permutation and bootstrap F-tests for the standardized Procrustes datasets to assess shape differences between groups (Sheets 2004a). We performed PCs analysis on the combined dataset to obtain and visualize the main axes of variation in the sample. We examined the covariation structure of both APVs and PCVs using correlation and partial correlation analysis (using JMP 5.1.1) to quantify the strength and trend of correlations in size and shape between particular modules while holding constant the effects of other variables. In the partial correlation analysis, each correlation controls for all other correlations in the analyzed set. Partial correlations are calculated as the negative of the inverse correlation matrix scaled to unit diagonal. Because PCs within regions are uncorrelated, multiple PCVs from the same region were excluded when determining how particular PCs relate to variation in other regions. The critical $r$ for both correlations and partial correlations at $\alpha=0.05$ was adjusted for the number of correlations in each matrix. To obtain the among-genotype correlations for all variables, we obtained the mean values across genotypes.

To determine the influence of each PCV and APV on shape variation, we performed multiple regressions of the partial warps for each region on those from the other regions. We also used the Procrustes distance variation as a measure of shape variation about the mean and regressed this measure on the PCVs and APVs using the IMP module 3D Regress6 (Sheets 2002). Following Zelditch et al. (2006), we tested the PCs derived from each Procrustes dataset for statistical distinctiveness using 3DPCA from the IMP statistical package (Sheets 2004b).

\section{RESULTS}

The combined sample for the five different mouse strains exhibits considerable variation in both the APVs and PCVs
(Figs. 3 and 4). Genotypes differ in overall shape as determined by the permutation and bootstrap F-tests after removing the allometric component of shape variation (Fig. 5). Two-way ANOVAs for genotype and sex revealed that all APVs and PCVs differ significantly among genotypes (Table 2). Only relative basicranial size and neurocranial PC3 differed between sexes after Bonferronni adjustment for multiple comparisons. Sex accounted for between $0 \%$ and $12 \%$ of the total variance for each variable. All variables vary significantly among genotypes (Table 2). The variance of the combined sample explained by genotype ranges from $12 \%$ to $66 \%$. The pairwise comparisons revealed most notably that the Mceph mice have significantly larger endocranial volumes than the wild types; the $\mathrm{bm} / \mathrm{bm}$ mice have significantly shorter cranial bases $(P<0.01)$; the $C r f 4$ mice have significantly shorter faces, but also have shorter basicrania and smaller heads $(P<0.01)$; and the Pten ${ }^{\text {flox } / \text { flox }} \times$ Col2alCre mice have longer basicrania than C57BL/6J wild types, but shorter basicrania than their littermate controls (indicating that the Pten mutation actually shortens the basicranium; $P<0.01)$. Genotypes also varied significantly in centroid size $(P<0.01)$.

The shape variation described by the regional PCs is summarized in detail in Table 3. Only the first PC is statistically distinct from the other components of shape variation as determined by resampling. Thus, the second and third components within each region describe axes of equivalent length (Zelditch et al. 2006). It is notable that PC1 for all three regions describes several covarying aspects of shape, but in all cases this first PC dominantly influenced by relative width (Fig. 4, A-C). The PC1s of all three regions covary strongly with each other (Fig. 6A), as do regressions of size-corrected widths (Fig. 6B). For the neurocranium and basicranium, 


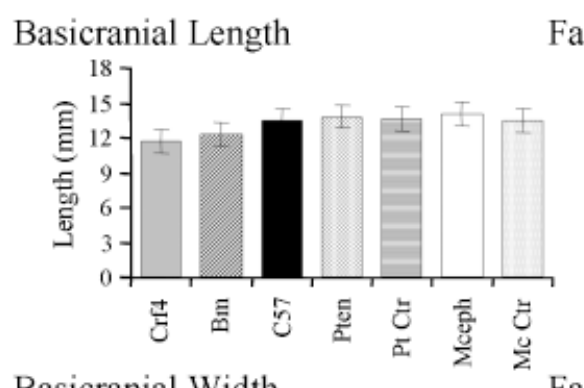

Facial Length

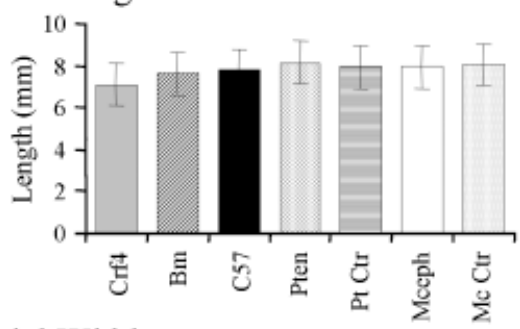

Facial Width
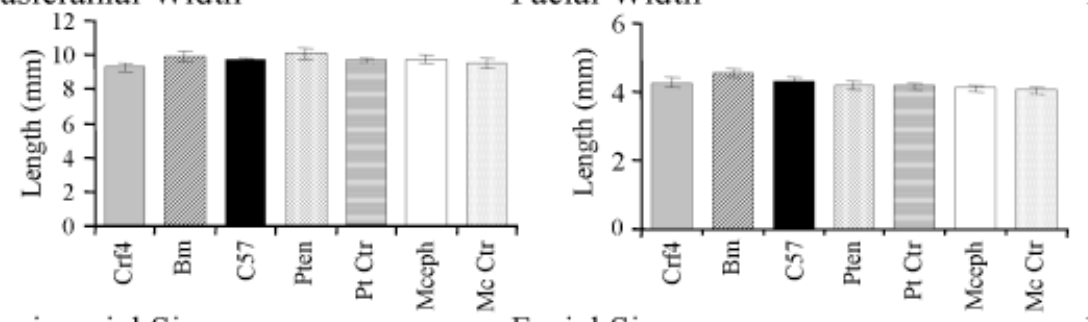

Facial Size

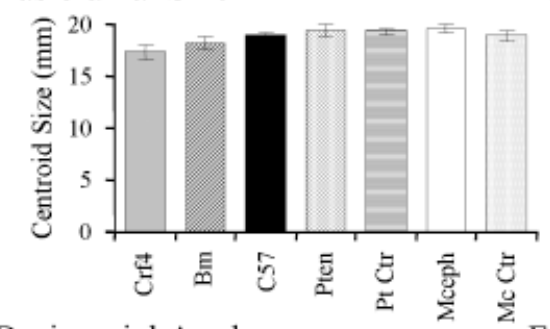

Basicranial Angle

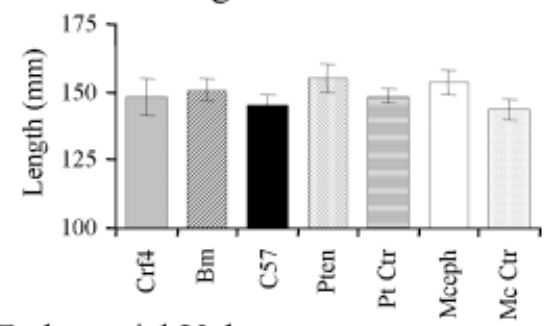

Endocranial Volume
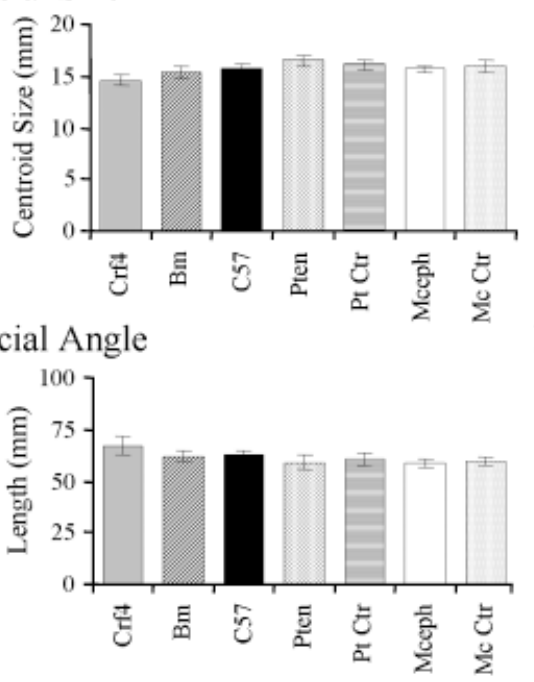

Neurocranial Length

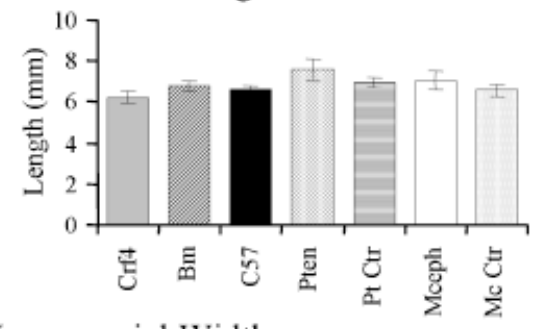

Neurocranial Width

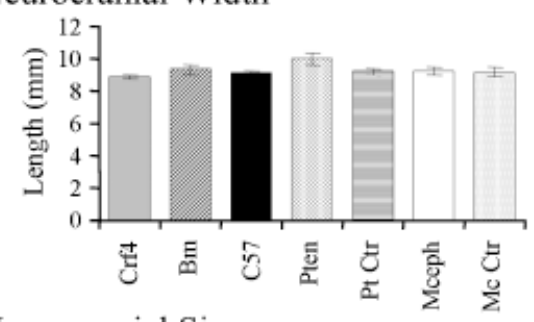

Neurocranial Size

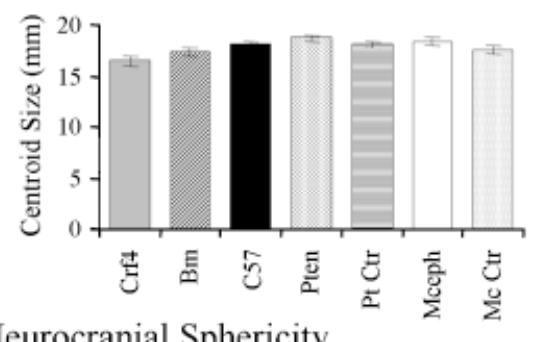

Neurocranial Sphericity

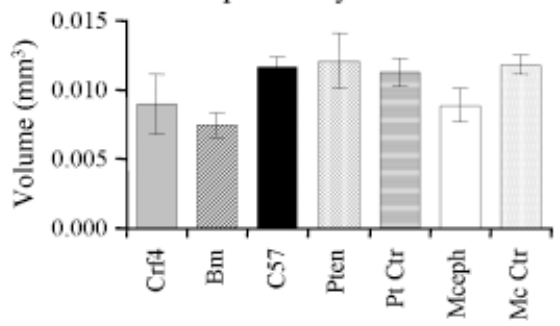

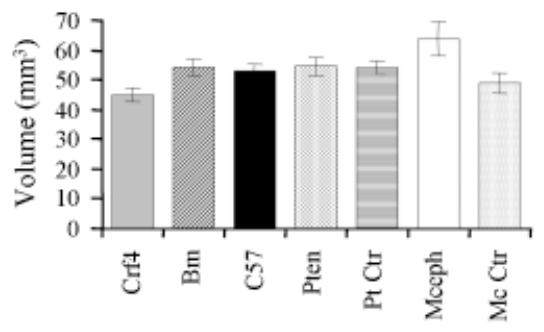

Fig. 3. Means and standard deviations for key a priori variables for all strains. Sexes are lumped.

these correlations are significant at the among-genotype level at $\alpha=0.1$ but not after Bonferroni's correction for multiple comparisons.

Several other significant partial correlations among PCVs and APVs capture axes of covariation among regions. For instance, mice with relatively larger and more spherical neu- rocrania have flatter cranial bases, which is reflected both via direct measures of the cranial base angle and $\mathrm{PCl}$ of the basicranium (Fig. 7, A-C). As the mouse cranial base is retroflexed (extended) by comparison with humans, this direction of change is consistent with Beigert's hypothesized relationship between brain size and basicranial shape in hom- 


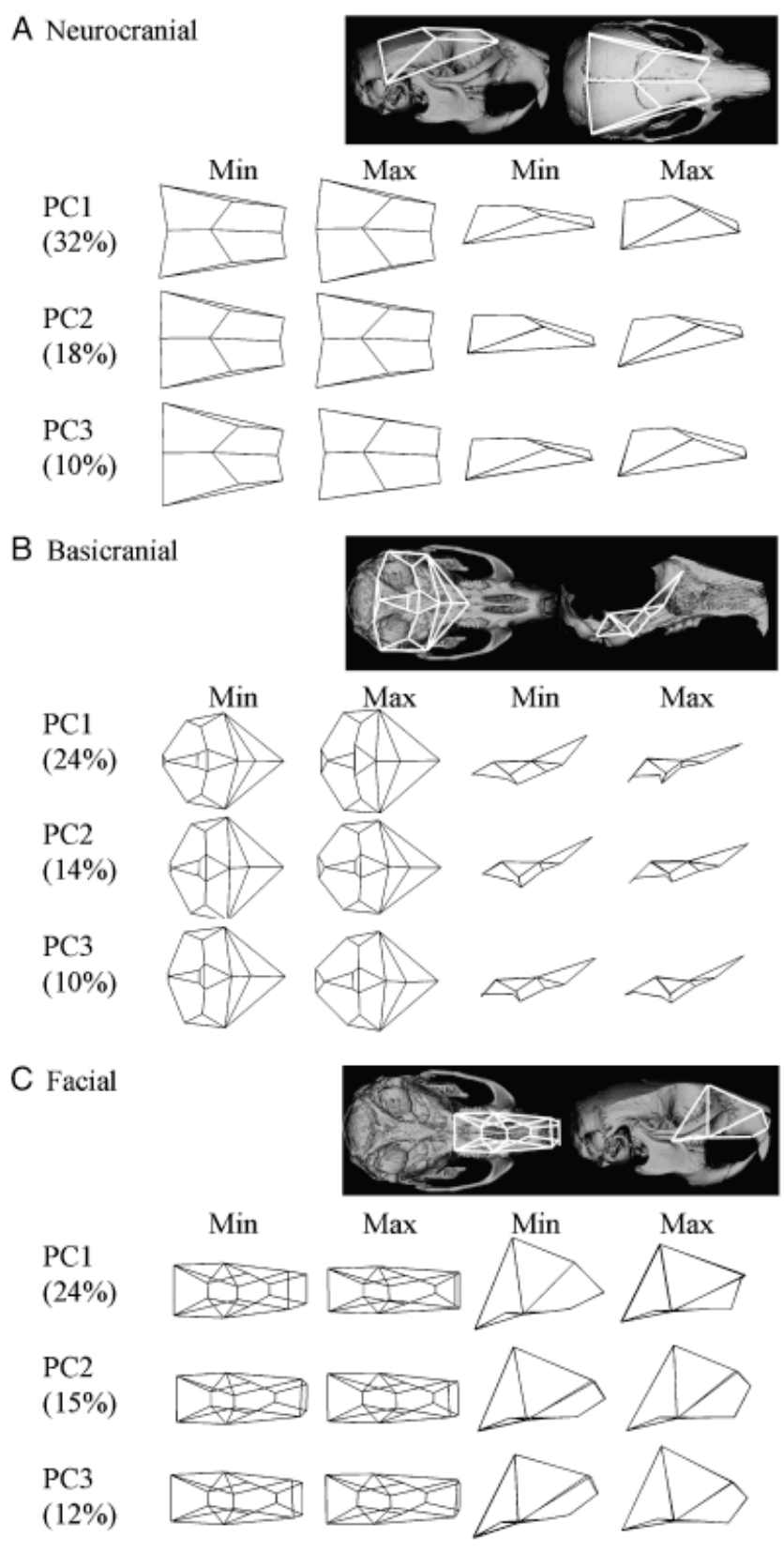

Fig. 4. Wireframe deformations depicting variation along the first three principal components (PCs) for each region. Procrustes superimposition were performed separately for each region. The allometric component of shape variation was then removed before running the principal components.

inids (Biegert 1963). These correlations are also significant when uncorrected for multiple comparisons at the amonggenotype level despite the small number of mutants used in this study $(\alpha=0.05)$.

Correlation and partial correlation analyses reveal a complex pattern of within-region integration and a highly struc- tured pattern of covariation among regions. Relationships with partial correlations $>0.4$, which are all significant at $P<0.01$ after Bonferroni's adjustment for multiple comparisons, are summarized in Fig. 8. Table 4 shows the correlations and partial correlations for the PCVs while Table 5 shows the correlations and partial correlations for the APVs. A correlation and partial correlation matrix of all included variables is provided as an Appendix A. These correlations corroborate the observation that the relative widths of each region dominate the overall pattern of covariation within the sample. The face varies more independently than the other regions of the cranium, but covaries most strongly in terms of width, especially with neurocranial shape. In addition, there is a strong correlation between the basicranial angle and shape and neurocranial size and shape (see Appendix A for correlations and Fig. 7). The dominance of widths in terms of the overall pattern of integration is also quantified by a multiple regression analysis for regional shape variation against all PCVs and APVs. Z-transformed correlations for each PCV and APV against Procrustes distance (Fig. 9) show that the first regional PCs and regional widths are the strongest determinants of shape variation in other regions. In this analysis, basicranial angle and neurocranial sphericity are also significant determinants of overall shape variation in other regions.

\section{DISCUSSION}

The above results reinforce those of previous studies that the cranium is a highly integrated structure, characterized by complex covariation both within and between regions (e.g., Cheverud 1982a, 1989, 1995; Enlow 1990; Lieberman et al. 2002; Bookstein et al. 2003; Gonzalez-Jose et al. 2004; Ackermann 2005). However, our results also indicate that cranial covariation is predictably structured in a significant way. Genetic perturbations that proximately influence the size and shape of particular cranial units such as the neurocranium, face or basicranium have unequal but consistent (and thus predictable) effects on other regions of the cranium. We can therefore reject both the null hypotheses, that developmental changes to a particular region have either only localized effects $\left(\mathrm{H}_{\mathrm{N} 1}\right)$, or highly distributed and widespread effects $\left(\mathrm{H}_{\mathrm{N} 2}\right)$. Instead, certain interactions appear to structure much of the covariation evident within the mouse sample studied here. The most dominant of these covariations occur between the widths of neurocranium and basicranium and to a lesser extent between the width of the basicranium and face. Mice with wider basicrania have wider neurocrania and wider faces and vice versa. Importantly, the specific developmental causes for these epigenetic interactions can vary, but with similar consequences for overall cranial shape. Thus, independent mechanisms that increase brain size (e.g., the Mceph muta- 


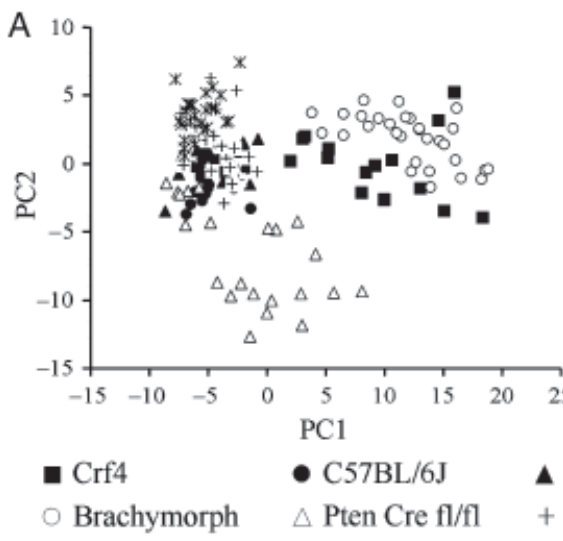

C

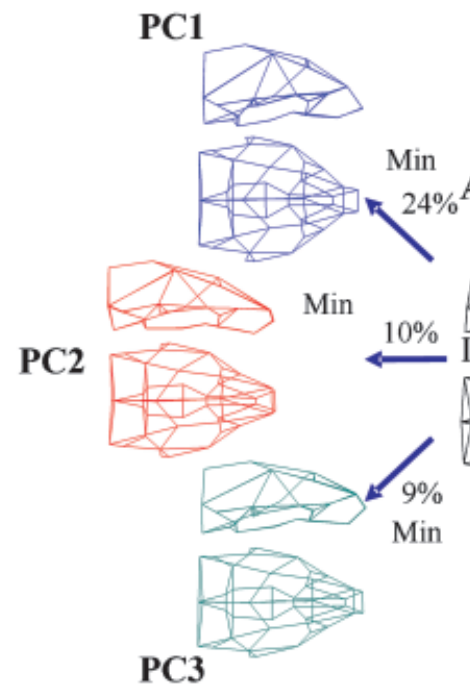

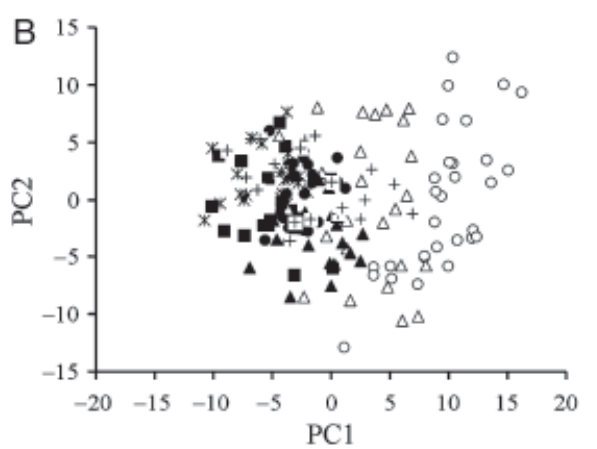

A Pten Wildtype $\quad$ * Mceph Wildtype or Heterozygote

$\mathrm{Mceph} / \mathrm{Mceph}$

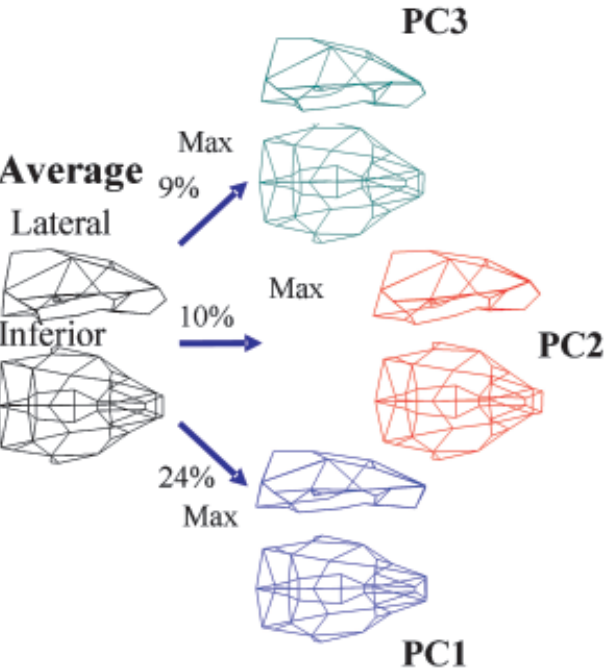

Fig. 5. Plots of principal component 1 (PC1) against PC2 for Procrustes data before (A) and after (B) removal of the allometric component of shape variation. (C) Wireframe deformations depicting variation along the first three principal components for the allometry free Procrustes data. $\mathrm{PC} 1$ is statistically distinct, but the lengths of $\mathrm{PC} 2$ and $\mathrm{PC} 3$ are equivalent. tion) or cranial base width (e.g., the Pten ${ }^{\text {flox } / \text { flox }} \times$ Col2al-Cre or $b m / b m$ mutations) all have the same general effect: to increase basicranial or neurocranial width, and thereby widen the face.

The experimental design used here also attempted to address how the basic architecture of the cranium and differences in regional growth processes structure epigenetic interactions between cranial units. As noted above, the basicranium is sometimes hypothesized to dominate craniofacial integration because it is the only part of the skull to grow endochondrally, and/or because it lies between the face and neurocranium $\left(\mathrm{H}_{\mathrm{A}}\right)$. Alternatively, the brain may have dominant effects on integration because of its disproportionate size $\left(\mathrm{H}_{\mathrm{B}}\right)$ and/or its early and rapid development; or the face may have dominant effects on integration because of its more extended skeletal growth trajectory $\left(\mathrm{H}_{\mathrm{C}}\right)$. This study most clearly rejects the last of these hypotheses because, for the most part, aspects of facial shape have fewer and weaker partial correlations with aspects of neurocranial and basicranial shape than these regions have with each other (Fig. 3A).
This independence may help explain why the face is the most variable part of the skull in many species, including humans (Howells 1973). Nevertheless, variation in the face does covary with other aspects of cranial shape, as previously hypothesized (Lieberman and McCarthy 1999; Lieberman et al. 2000), particularly the cranial base angle. However, hypotheses that the brain or basicranium have particularly dominant effects on cranial integration are not easily ranked because these two units covary so strongly in multiple ways. Our results support the view that the basicranium and neurocranium act in many ways as two linked components of an integrated complex (Lieberman et al. 2000).

One complication of this analysis is that the perturbations that generate much of the sample's variation sample are difficult to compare in terms of the magnitude of their effects because of their qualitative differences. The mceph mutation has a large phenotypic effect, but is manifested late in ontogeny (postnatally) rather than prenatally. Conversely, the $\mathrm{bm} / \mathrm{bm}$ mutation may have a smaller magnitude of effect, but its influence on overall craniofacial shape may be dispropor- 
Table 2. Two-Way ANOVA results for comparisons of APVs and PCVs by sex and genotypes $(\mathrm{df}=153$ for all tests)

\begin{tabular}{|c|c|c|c|c|c|c|c|c|}
\hline \multirow[b]{2}{*}{ Variable } & \multicolumn{4}{|c|}{ Sex } & \multicolumn{4}{|c|}{ Genotype } \\
\hline & MS & $F$ & $\begin{array}{c}\% \text { Variance } \\
\text { explained }\end{array}$ & $P$-value* & MS & $F$ & $\begin{array}{c}\% \text { Variance } \\
\text { explained }\end{array}$ & $P$-value* \\
\hline Basicranial angle & 27.46 & 2.10 & 1.86 & 0.10 & 441.96 & 33.80 & 40.01 & $<0.001$ \\
\hline Basicranial length & 0.32 & 4.55 & 7.15 & 0.00 & 0.66 & 9.43 & 19.74 & $<0.001$ \\
\hline Basicranial width & 0.02 & 0.39 & 0.43 & 0.76 & 1.31 & 23.18 & 33.88 & $<0.001$ \\
\hline Basicranial size & 0.32 & 5.88 & 9.56 & $<\mathbf{0 . 0 0 1}$ & 0.28 & 5.17 & 11.21 & $<0.001$ \\
\hline Neurocranial length & 0.26 & 2.34 & 2.50 & 0.08 & 3.51 & 31.12 & 44.38 & $<0.001$ \\
\hline Neurocranial width & 0.11 & 1.97 & 1.45 & 0.12 & 3.53 & 61.26 & 60.32 & $<0.001$ \\
\hline Endocranial volume & 29.85 & 3.87 & 2.87 & 0.01 & 385.56 & 49.92 & 49.50 & $<0.001$ \\
\hline Neurocranial size & 0.18 & 3.77 & 3.05 & 0.01 & 2.49 & 51.25 & 55.32 & $<0.001$ \\
\hline Sphericity & 0.000003 & 1.61 & 1.15 & 0.19 & 0.000089 & 50.76 & 48.25 & $<0.001$ \\
\hline Facial angle & 21.14 & 2.57 & 3.06 & 0.06 & 63.89 & 7.76 & 12.34 & $<0.001$ \\
\hline Facial width & 0.07 & 4.19 & 3.66 & 0.01 & 0.69 & 43.64 & 50.85 & $<0.001$ \\
\hline Facial length & 0.11 & 1.97 & 1.45 & 0.12 & 3.53 & 61.26 & 60.32 & $<0.001$ \\
\hline Facial size & 0.08 & 1.41 & 1.76 & 0.24 & 1.37 & 22.95 & 38.28 & $<0.001$ \\
\hline Basicranium PC1 & 1.08 & 0.19 & 0.16 & 0.90 & 197.03 & 34.88 & 38.11 & $<0.001$ \\
\hline Basicranium PC2 & 7.64 & 1.35 & 2.10 & 0.26 & 52.26 & 9.27 & 19.13 & $<0.001$ \\
\hline Basicranium PC3 & 6.13 & 1.93 & 2.51 & 0.13 & 30.90 & 9.71 & 16.89 & $<0.001$ \\
\hline Face PC1 & 1.70 & 0.82 & 0.29 & 0.49 & 291.22 & 140.34 & 66.08 & $<0.001$ \\
\hline Face PC2 & 12.93 & 4.04 & 3.57 & 0.01 & 144.46 & 45.13 & 53.19 & $<0.001$ \\
\hline Face PC3 & 8.98 & 1.79 & 2.91 & 0.15 & 29.08 & 5.80 & 12.56 & $<0.001$ \\
\hline Neurocranium PC1 & 1.66 & 0.65 & 0.38 & 0.58 & 198.39 & 78.32 & 61.23 & $<0.001$ \\
\hline Neurocranium PC2 & 1.33 & 0.45 & 0.53 & 0.72 & 44.45 & 14.93 & 23.76 & $<0.001$ \\
\hline Neurocranium PC3 & 16.78 & 9.16 & 12.09 & $<0.001$ & 30.82 & 16.82 & 29.61 & $<0.001$ \\
\hline
\end{tabular}

*Bolded values are significant at $\alpha=0.05$ after Bonferroni's adjustment for 22 comparisons. Values below 0.05 but not bolded are above the adjusted $P$-value of 0.0023 .

APV, a priori variables; PCV, principal component variables.

tionately large by influencing chondrogenesis earlier in ontogeny. Nonetheless, the variation produced by these mutations identifies axes of phenotypic variation that relate to key developmental processes such as chondrocranial or brain growth. By looking for these same axes of phenotypic variation in natural populations, it may be possible to determine empirically the contribution of these developmental processes to variation in natural populations.

Table 3. Shape variation represented by the regional PCVs

\begin{tabular}{ll}
\hline & \multicolumn{1}{c}{ Shape variation } \\
$\begin{array}{ll}\text { Basicranium } \\
\text { PC1 }\end{array}$ & $\begin{array}{l}\text { The relative width of the basicranium, basicranial angle (basion-mid-sphenoidal suture-foramen caecum), the angle of the } \\
\text { petrous temporal to the midline, and length of the sphenoid } \\
\text { Length of the basi-occipital; angle formed in the transverse plane between the mid-sphenoidal suture and the posterior } \\
\text { origin of the zygomatic arch }\end{array}$ \\
PC2 & $\begin{array}{l}\text { Length of the presphenoid and the angle between the basion and the postero-medial extremity of the tympanic bulla } \\
\text { PC3 }\end{array}$ \\
$\begin{array}{ll}\text { Neurocranium } \\
\text { PC1 }\end{array}$ & $\begin{array}{l}\text { Height and width of the posterior cranial vault } \\
\text { PC2 }\end{array}$ \\
PC3 & $\begin{array}{l}\text { Length of the anterior (frontal) portion of the vault and the orientation of the frontal and parietal squamae in lateral view } \\
\text { Face }\end{array}$ \\
PC1 & Width of the palate, the height of the face, the length of the incisive foramen and the orientation of the premaxilla \\
PC2 & Lengths of the palate and maxilla \\
PC3 & Facial angle and facial asymmetry
\end{tabular}

PC, principal component; PCV, principal component variables. 


\section{A Covariation Regional PCAs}

\section{i. Among-Individual Variation}
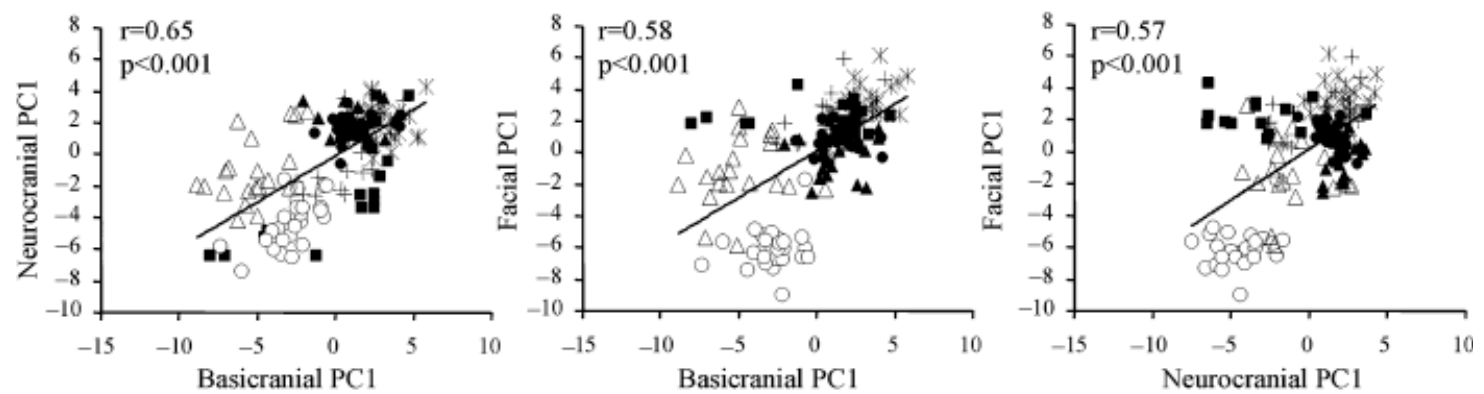

ii. Among-Genotype Variation
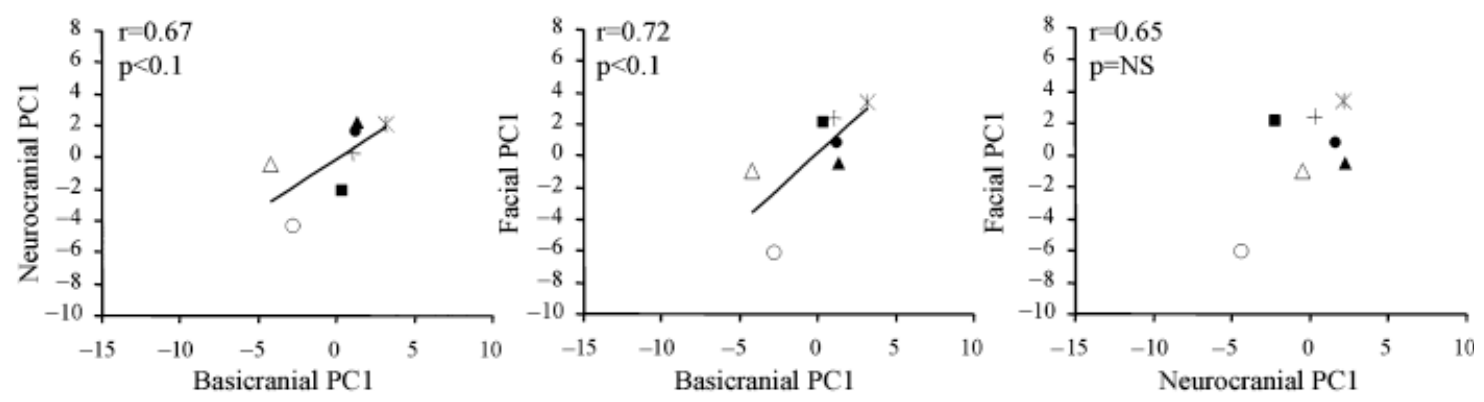

B Covariation Among Relative Widths

\section{i. Among-Individual Variation}

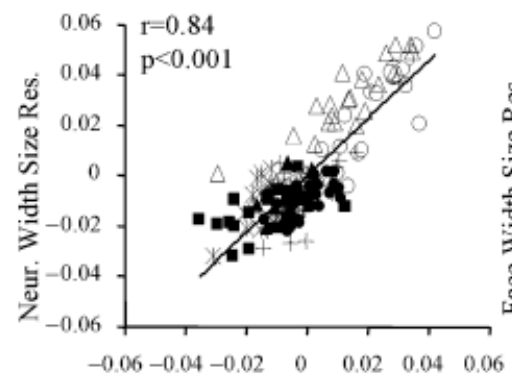

Basi. Width Size Res.

ii. Among-Genotype Variation

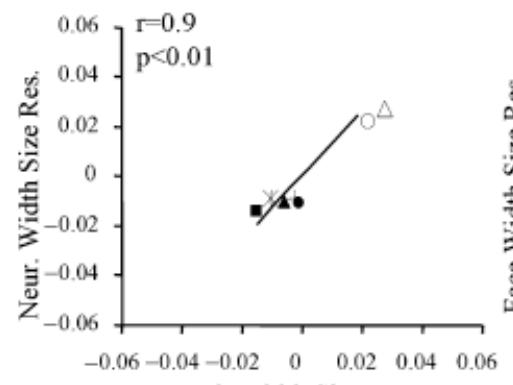

Basi. Width Size Res.

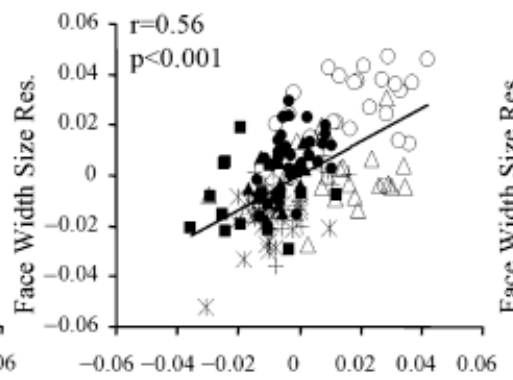

Basi. Width Size Res.

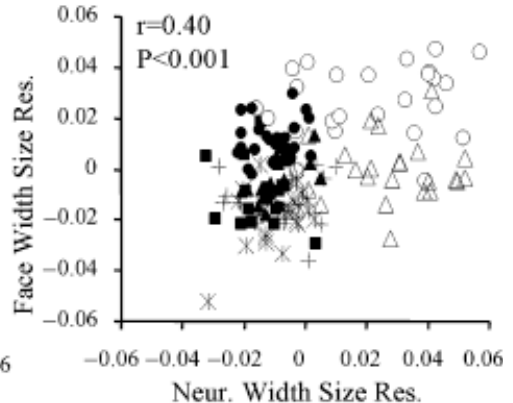

Neur. Width Size Res.

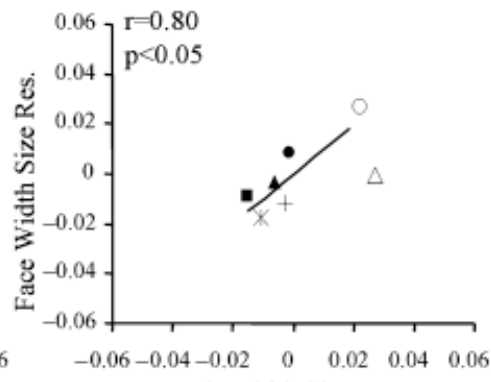

Basi. Width Size Res.

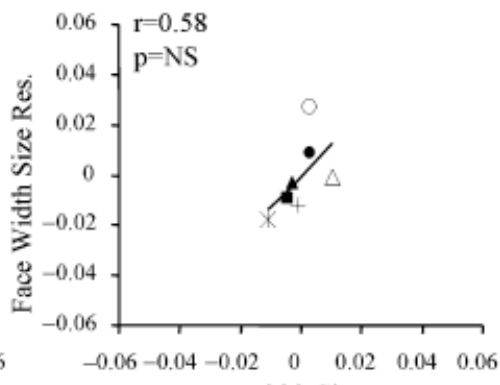

Neur. Width Size Res.

Fig. 6. Relationships for among-individual and among-genotype variation for the first components of regional variation and regional widths. Principal component variables (PCVs) have allometric shape variation removed and the widths are the residuals of the logtransformed widths regressed on cranial centroid size. Size is thus removed and the correlations are not due to common variation in cranial size. The symbols on the scatterplots are the same as in Fig. 2. 
A Neurocranial Length and Basicranial Angle

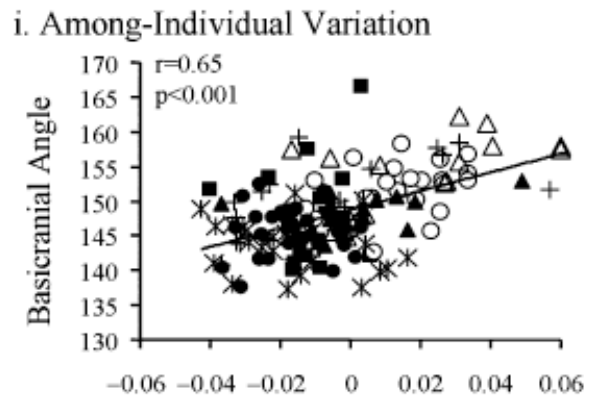

Res. Log. Neuro. Length

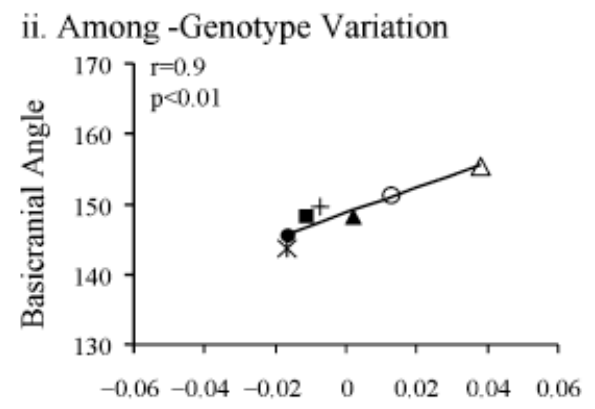

Neur. Length Res.

B Neurocranial Centroid Size and Basicranial Angle

i. Among-Individual Variation

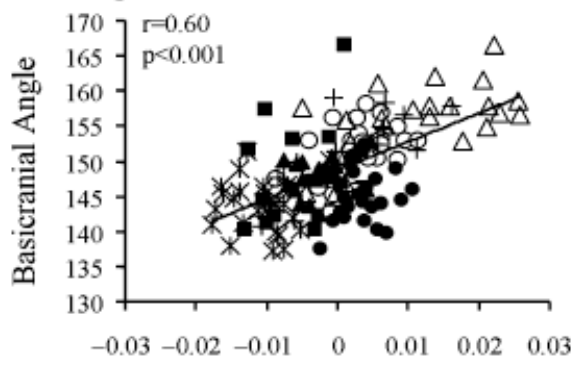

Res. Log. Neuro. Size ii. Among -Genotype Variation

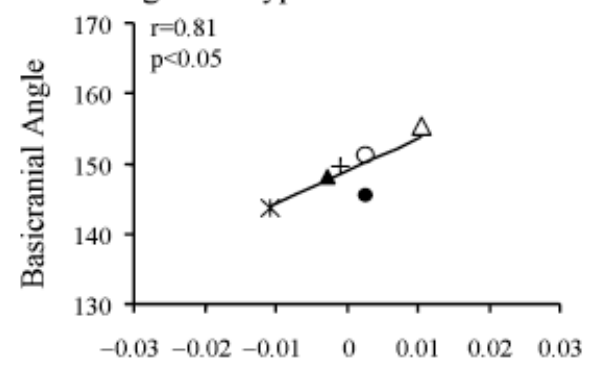

Neur. Centroid Size Res.

\section{Neurocranial Size and Basicranial PC1}

\section{i. Among-Individual Variation}

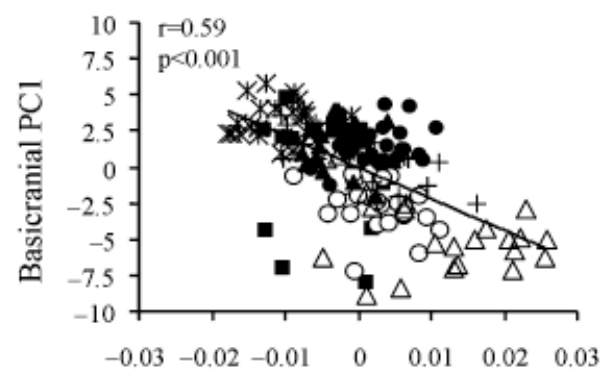

Res. Log. Neuro, Size ii. Among -Genotype Variation

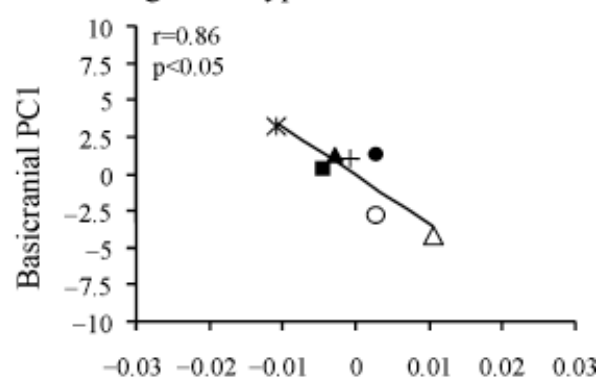

Res. Log Neuro Size
Fig. 7. Relationships between the basicranium and neurocranium. The linear measurements and centroid sizes are log transformed and then regressed on cranial centroid size and basicranial principal components 1 (PC1) has the allometric component of shape variation removed. Size is thus removed and the correlations are not due to common variation in cranial size. The symbols on the scatterplots are the same as in Fig. 2.
A second consideration is the possibility that the mutations sampled here may have direct effects on more than one region of the skull. This is certainly true of the Crf4 mutation and is possible to a minor extent for both the $\mathrm{bm} / \mathrm{bm}$ mutants and the Pten flox/flox $\times$ Col2al-Cre mice. In the two latter cases, it is safe to assume that the major direct effects are on the chondrocranium and that the effect on the dermatocranial elements is largely secondary. For the Pten flox/flox mice, it is possible that Pten is deleted in the growing brain. However, the endocranial volumes are not larger in these mutants indicating that this is not a concern. Given that for all but one of the mutants used, we are confident that one region is predominantly affected by the direct developmental perturb- ation, it is highly unlikely that the patterns of covariation observed here are idiosyncratic products of the particular pattern of effects produced by the genetic variation in this sample. As a preliminary test to exclude this possibility, it is confirming that the among-genotype correlations for most of the axes of covariation observed are significant. However, a larger study with many more mutations with repeated sampling of similar developmental perturbations (e.g., multiple mutations that affect brain growth or cartilage growth) is needed to completely eliminate this possibility.

Although the cranium is a highly integrated structure, the dominant patterns of integration reported here highlight how a few key developmental processes can play disproportionate 


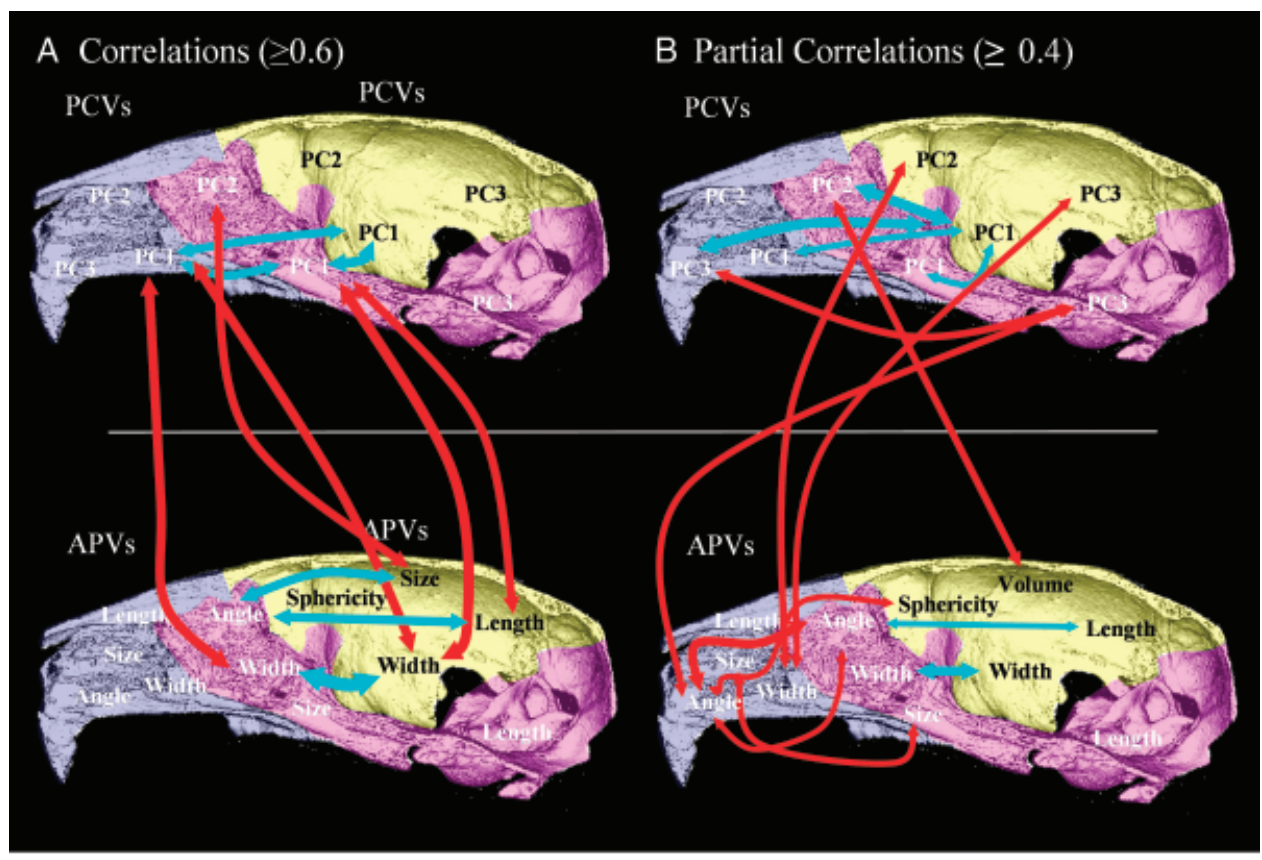

Fig. 8. (A) Largest correlations and partial correlations among a priori variables (APVs) and principal component variables (PCVs) across regions. Line thickness is proportional to the correlation strength. Within-region correlations between APVs and the PCVs are excluded from this diagram. Within-region APV correlations are included. Positive correlations are denoted by black lines while negative correlations are shown in red. and nonrandom roles in influencing overall craniofacial shape. Notably, because the basicranium is both the floor of the neurocranium and the posterior margin of the face, variations in basicranial width and to a lesser extent the angle of the cranial base cannot vary independently of the width and shape of the neurocranium and the face. However, we stress that these epigenetic interactions are far downstream of the primary genetic perturbations that are proximately responsible for the variation. For example, the Mceph mutation used in this study generates a larger brain and hence a wider neurocranium, basicranium, and face. But other mutations that affect brain size would have the same shape effects, as do mutations that increase basicranial width relative to length and thus lead to a relatively wider face and neurocranium (e.g., proteoglycan undersulfation in the $\mathrm{bm} / \mathrm{bm}$ mice, or premature closure of the basicranial synchondroses in the Pten ${ }^{\text {flox/flox }} \times$ Col2al-Cre mice). Indeed, any mutations that influence endochondral growth in the cranial base can potentially lead to a similar suite of integrated shifts depending on the timing and magnitude of the effect. Endochondral growth as a developmental process is, therefore, as ontologically relevant to explanation of the developmental basis for

Table 4. Correlations and partial correlations for principal components of within-region variation

\begin{tabular}{lcccccrrrr}
\hline & BC PC1 & BC PC2 & BC PC3 & FC PC1 & FC PC2 & FC PC3 & NC PC1 & NC PC2 & NC PC3 \\
\hline BC PC1 & - & - & - & $\mathbf{0 . 5 8}$ & -0.25 & -0.14 & $\mathbf{0 . 6 5}$ & -0.13 & $\mathbf{0 . 3 0}$ \\
BC PC2 & - & - & - & -0.16 & 0.07 & 0.02 & $-\mathbf{0 . 3 0}$ & 0.19 & -0.11 \\
BC PC3 & - & - & - & $-\mathbf{0 . 4 9}$ & -0.02 & -0.14 & -0.15 & -0.01 & -0.22 \\
FC PC1 & $\mathbf{0 . 3 6}$ & 0.05 & -0.17 & - & - & - & $\mathbf{0 . 5 7}$ & $\mathbf{0 . 4 0}$ & 0.25 \\
FC PC2 & $-\mathbf{0 . 3 6}$ & -0.11 & $-\mathbf{0 . 5 0}$ & - & - & - & -0.09 & 0.10 \\
FC PC3 & -0.03 & 0.12 & 0.01 & - & - & -0.15 \\
NC PC1 & $\mathbf{0 . 4 3}$ & -0.02 & 0.04 & $\mathbf{0 . 4 1}$ & $\mathbf{0 . 7 1}$ & $\mathbf{0 . 6 8}$ & - & -0.18 & - \\
NC PC2 & $-\mathbf{0 . 2 8}$ & -0.27 & 0.00 & $-\mathbf{0 . 3 0}$ & -0.08 & -0.07 & - & - \\
NC PC3 & 0.22 & 0.17 & -0.03 & 0.26 & $\mathbf{0 . 3 6}$ & $\mathbf{0 . 3 8}$ & - & - \\
\hline
\end{tabular}

Upper right half of matrix contains raw correlation coefficients. The lower left contains partial correlations controlling for all variables except the PCs within the same region. As the within-region correlations were excluded, the partial correlation matrix is not symmetrical. The values reported are the average of the upper right and lower left halves of the partial correlation matrix. To obtain the average, we Fisher transformed the $r$ 's, obtained the average, and then transformed the resulting value back to $r$. Bolded values are significant at $\alpha=0.01$ after Bonferroni's adjustment for 29 comparisons. $\mathrm{PC}$, principal component. 


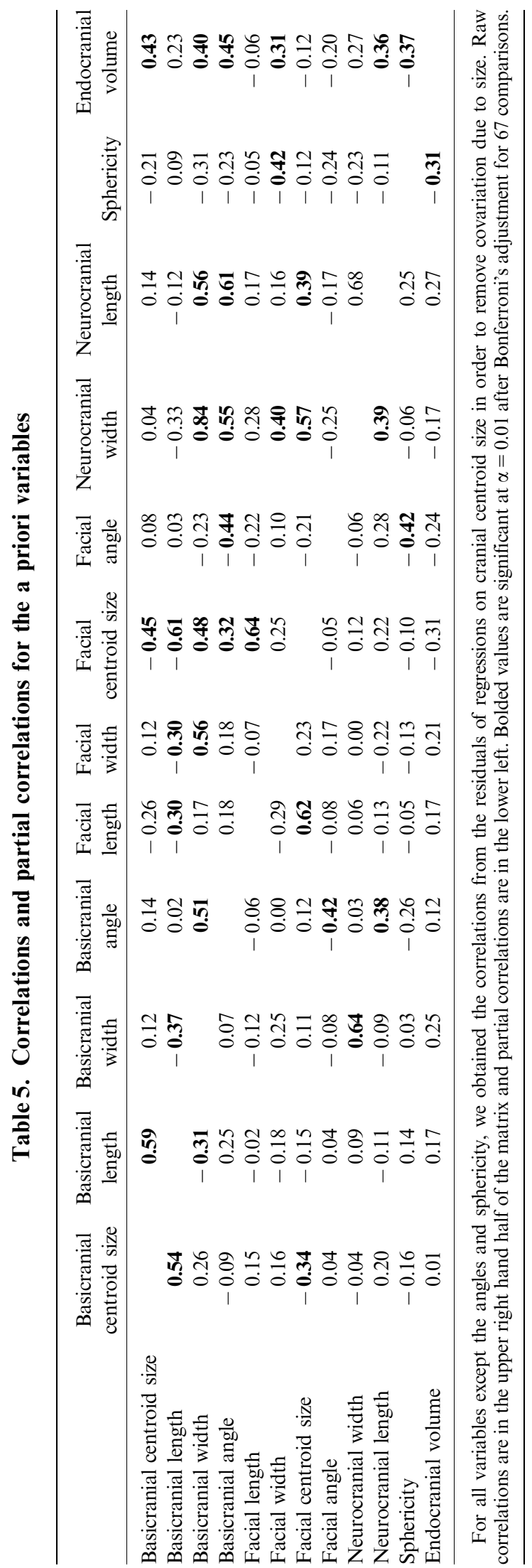

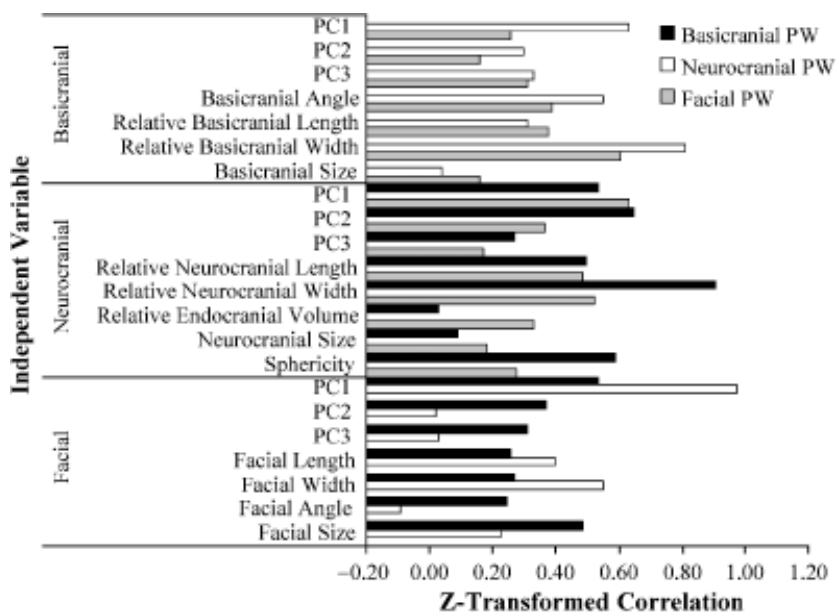

Fig. 9. Z-transformed correlations between a priori variables and principal component variables and total shape variation (Procrustes distance) within regions.

evolutionary change as the underlying mutations. Thus, the ways in which craniofacial shape can vary are channeled by the basic architecture of the cranium, and by the fundamental interactions through which regions of the cranium interact in order to accommodate each other's transformations in growth and shape.

Evidence that complex phenotypic variation in the cranium is structured to a significant degree by a restricted set of epigenetic pathways has important implications for the evolvability of complex traits. Although there is considerable genetic variation within any population that can lead to morphogenetic variation in the cranium, the phenotypic variability we observe is not random and is highly structured because it arises from a manageably small number of epigenetic interactions. Many craniofacial variations derive from processes that cause variations in brain growth, basicranial length and width, facial size, and so on. These key epigenetic pathways are, in essence, developmental constraints that limit the generation of phenotypic variation (Maynard Smith et al. 1985), but which also help skulls become integrated structures capable of simultaneously growing and functioning. For example, the strong covariation among the widths of the neurocranium, basicranium, and face help align the temporomandibular joint with the face through just a few interactions (e.g., the width of the brain influences the width of the middle cranial fossa, which influences facial width). Such constraints may explain why many of the documented variations in mammalian skull form among mammals as diverse as dogs and humans have repeatedly been shown to be related to a few key variables including relative brain size, cranial width, cranial base angle, cranial base length, and facial length (Weidenreich 1941; Ross and Ravosa 1993; Lieberman et al. 2000b; Chase et al. 2002). 
Finally, these results have implications for understanding various craniofacial dysmorphologies as well as for testing how genetic variation generates phenotypic variation in complex structures other than just the cranium. Although the developmental pathways that lead to morphogenesis of the many cranial components are dauntingly numerous and complex (and mostly unknown), their effects on how the cranium becomes an integrated whole are much less numerous and more predictable. As previously argued in a different context by Atchley and Hall (1991), it follows that understanding these epigenetic processes and how they structure and generate phenotypic variation in complex structures is key to understanding the developmental basis for evolutionary change. Variations in processes such as brain expansion, facial projection, and synchondrosis elongation are ontologically as important sources of explanation for evolutionary change as the underlying mutations that cause them. The underlying developmental genetic bases for morphogenetic shifts are clearly not irrelevant, but as so many mutations are channeled through a smaller set of developmental processes, unraveling how phenotypic units interact during development is fundamental to explaining the developmental bases for evolutionary diversity.

\section{Acknowledgments}

This paper is dedicated to the memory of W. W. Howells. Mice with floxed Pten alleles were a generous gift from T. W. Mak. This work was supported by National Science and Engineering Research Council grant \#238992 and funding Genome Canada to B. H.; the American School of Prehistoric research to D. E. L.; and the Canadian Institutes of Health Research to F .R. J.. F. R. J. was the recipient of a Canada Research Chair award, and A. F.-H. held a fellowship from the Alberta Heritage Foundation for Medical Research. We thank David Pilbeam, Brian Hall, Chris Klingenberg, and Nathan Young for critical comments. Supporting Grant Information: National Science and Engineering Grant 238992-02, Canadian Foundation for Innovation Grant \#3923, Alberta Innovation and Science Grant \#URSI-01-103-RI (B.H.), American School of Prehistoric (D. E. L.) and Canadian Institutes of Health Research Grant (F. R. J.)

\section{REFERENCES}

Ackermann, R. R. 2005. Ontogenetic integration of the hominoid face. J. Hum. Evol. 48: 175-197.

Atchley, W. R., and Hall, B. K. 1991. A model for development and evolution of complex morphological structures. Biol. Rev. 66: 101-157.

Baughan, B., Demirjian, A., Levesque, G. Y., and Lapalme-Chaput, L. 1979. The pattern of facial growth before and during puberty, as shown by French-Canadian girls. Ann. Hum. Biol. 6: 59-76.

Biegert, J. 1963. The evaluation of characteristics of the skull, hands and feet for primate taxonomy. In S. L. Washburn (ed.). Classification and Human Evolution. Aldine, Chicago, pp. 116-145.

Bookstein, F. L., Gunz, P., Mitteroecker, P., Prossinger, H., Schaefer, K., and Seidler, H. 2003. Cranial integration in Homo: singular warps analysis of the midsagittal plane in ontogeny and evolution. J. Hum. Evol. 44: $167-187$.
Carroll, S. B., Grenier, J. K., and Weatherbee, S. D. 2005. From DNA to Diversity. Blackwell Publishing, Malden, MA.

Chase, K., et al. 2002. Genetic basis for systems of skeletal quantitative traits: principal component analysis of the canid skeleton. Proc. Natl. Acad. Sci. USA 99: 9930-9935.

Cheverud, J. M. 1995. Morphological integration in the saddle-back tamarin (Saguinus fuscicollis) cranium. Am. Nat. 145: 63-89.

Cheverud, J. M. 1989. A comparative analysis of morphological variation patterns in the papionins. Evolution 43: 1737-1747.

Cheverud, J. M. 1982a. Phenotypic, genetic, and environmental integration in the cranium. Evolution 36: 499-516.

Cheverud, J. M. 1982b. Phenotypic, genetic, and environmental integration in the cranium. Evolution 36: 499-516.

Cohen, M. M. Jr., Walker, G. F., and Phillips, C. 1985. A morphometric analysis of the craniofacial configuration in achondroplasia. J. Craniofac. Genet. Dev. Biol. 1 (suppl.): 139-165.

Davidson, E. H., et al. 2002. A genomic regulatory network for development. Science 295: 1669-1678.

De Beer, G. 1937. The Development of the Vertebrate Skull. Clarendon Press, Oxford.

Diez, M., et al. 2003. MRI and in situ hybridization reveal early disturbances in brain size and gene expression in the megencephalic (mceph/ mceph) mouse. Eur. J. Neurosci. 18: 3218-3230.

Enlow, D. H. 1990. Facial Growth. Saunders, Philadelphia.

Farkas, L. G., Posnick, J. C., and Hreczko, T. M. 1992. Growth patterns of the face: a morphometric study. Cleft Palate. Craniofac. J. 29: 308-315.

Gonzalez-Jose, R., Van Der, M. S., Gonzalez-Perez, E., and Hernandez, M. 2004. Patterns of phenotypic covariation and correlation in modern humans as viewed from morphological integration. Am. J. Phys. Anthropol. 123: 69-77.

Hallgrímsson, B., Brown, J., Ford-Hutchinson, A., Sheets, D., Zelditch, M. L., and Jirik, F. R. 2006. The Brachymorph Mouse and the developmental-genetic basis for canalization and morphological integration. Evol. Dev. 8: 61-73.

Hallgrímsson, B., Dorval, C. J., Zelditch, M. L., and German, R. Z. 2004a Craniofacial variability and morphological integration in mice susceptible to cleft lip and palate. J. Anat. 205: 501-517.

Hallgrímsson, B., Willmore, K., Dorval, C., and Cooper, D. M. 2004b. Craniofacial variability and modularity in macaques and mice. J. Exp. Zool. B Mol. Dev. Evol. 302: 207-225.

Howells, W. W. 1973. Cranial Variation in Man; a Study by Multivariate Analysis of Patterns of Difference Among Recent Human Populations. Peabody Museum of Archaeology and Ethnology, Harvard University, Cambridge, MA.

Kangas, A. T., Evans, A. R., Thesleff, I., and Jernvall, J. 2004. Nonindependence of mammalian dental characters. Nature 432: 211-214.

Kile, B. T., et al. 2003. Functional genetic analysis of mouse chromosome 11. Nature 425: 81-86.

Kreiborg, S., et al. 1993. Comparative three-dimensional analysis of CTscans of the calvaria and cranial base in Apert and Crouzon syndromes. J. Craniomaxillofac. Surg. 21: 181-188.

Kurima, K., et al. 1998. A member of a family of sulfate-activating enzymes causes murine brachymorphism. Proc. Natl. Acad. Sci. USA 95: $8681-8685$

Lieberman, D. E., McBratney, B. M., and Krovitz, G. 2002. The evolution and development of cranial form in Homo sapiens. Proc. Natl. Acad. Sci. USA 99: 1134-1139.

Lieberman, D. E., and McCarthy, R. C. 1999. The ontogeny of cranial base angulation in humans and chimpanzees and its implications for reconstructing pharyngeal dimensions. J. Hum. Evol. 36: 487-517.

Lieberman, D. E., Pearson, O. M., and Mowbray, K. M. 2000. Basicranial influence on overall cranial shape. J. Hum. Evol. 291-315.

Lieberman, D. E., Pearson, O. M., and Mowbray, K. M. 2000a. Basicranial influence on overall cranial shape. J. Hum. Evol. 38: 291-315.

Lieberman, D. E., Ross, C. F., and Ravosa, M. J. 2000b. The primate cranial base: ontogeny, function, and integration. Am. J. Phys. Anthropol. (suppl. 31): 117-169.

Maynard Smith, J., et al. 1985. Developmental constraints and evolution. Quart. Rev. Biol. 60: 265-287. 
Moore, W. J., and Lavelle, C. L. B. 1974. Growth of the Facial Skeleton in the Hominoidea. Academic Press, London; NY.

Moss, M. 1997a. The functional matrix hypothesis revisited. 1. The role of mechanotransduction. Am. J. Orthodont. Dentofac. Orthoped. 112: 8-11.

Moss, M. 1997b. The functional matrix hypothesis revisited. 2. The role of an osseous connected cellular network. Am. J. Orthodont. Dentofac. Orthoped. 112: 221-226.

Moss, M. 1997c. The functional matrix hypothesis revisited. 3. The genomic thesis. Am. J. Orthodont. Dentofac. Orthoped. 112: 338-342.

Moss, M. 1997d. The functional matrix hypothesis revisited. 4. The epigenetic antithesis and the resolving synthesis. Am. J. Orthodont. Dentofac. Orthoped. 112: 410-417.

Moss, M. L., and Young, R. W. 1960. A functional approach to craniology. Am. J. Phys. Anthropol. 18: 281-292.

Opperman, L. A. 2000. Cranial sutures as intramembranous bone growth sites. Dev. Dyn. 219: 472-485.

Ovchinnikov, D. A., Deng, J. M., Ogunrinu, G., and Behringer, R. R. 2000. Col2al-directed expression of Cre recombinase in differentiating chondrocytes in transgenic mice. Genesis 26: 145-146.

Petersson, S., et al. 2003. Truncation of the shaker-like voltage-gated potassium channel, Kv1.1, causes megencephaly. Eur. J. Neurosci. 18: 3231-3240.

Rohan, J. W., Yokochi, C., and Hall-Craggs, E. C. B. 1988. Color Atlas of Anatomy: A Photographic Study of the Human Body. Igaku-Shoin, New York.

Ross, C. F., and Ravosa, M. J. 1993. Basicranial flexion, relative brain size, and facial kyphosis in nonhuman primates. Am. J. Phys. Anthropol. 91: 305-324.
Sansal, I., and Sellers, W. R. 2004. The biology and clinical relevance of the PTEN tumor suppressor pathway. J. Clin. Oncol. 22: 2954-2963.

Sheets, H. D. 2004a. IMP Simple3D.

Sheets, H. D. 2004b. IMP ThreeDPCA6.

Sheets, H. D. 2004c. IMP ThreeDStand6.

Sheets, H. D. 2002. IMP ThreeDRegress6.

Spector, J. A., et al. 2002. Dura mater biology: autocrine and paracrine effects of fibroblast growth factor 2. Plast. Reconstr. Surg. 109: 645-654.

Stamrud, L. 1959. External and internal cranial base. Acta Odontol. Scand. 17: 239-266.

ul Haque, M. F., et al. 1998. Mutations in orthologous genes in human spondyloepimetaphyseal dysplasia and the brachymorphic mouse. Nat. Genet. 20: 157-162.

Weidenreich, F. 1941. The Brain and its role in the phylogenetic transformation of the human skull. Trans. Am. Philos. Soc. 31: 320-442.

Wilkie, A. O., and Morriss-Kay, G. M. 2001. Genetics of craniofacial development and malformation. Nat. Rev. Genet. 2: 458-468.

Wilkins, A. S. 2002. The Evolution of Developmental Pathways. Sinauer Associates, Sunderland, MA.

Yu, J. C., Lucas, J. H., Fryberg, K., and Borke, J. L. 2001. Extrinsic tension results in FGF-2 release, membrane permeability change, and intracellular $\mathrm{Ca}^{++}$increase in immature cranial sutures. J. Craniofac. Surg. 12: 391-398.

Zelditch, M. L., Mezey, J., Sheets, H. D., Lundrigan, B. L., and Garland, T. Jr. 2006. Developmental regulation of skull morphology II: ontogenetic dynamics of covariance. Evol. Dev. 8: 46-60. 


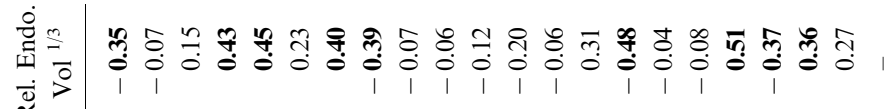

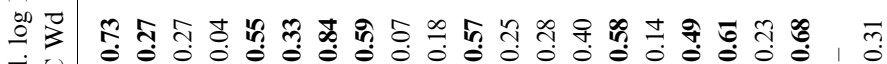

远

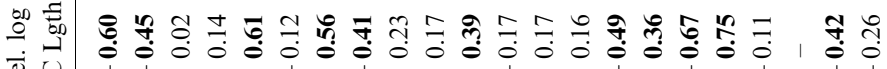

$\stackrel{\vec{s}}{Z}$

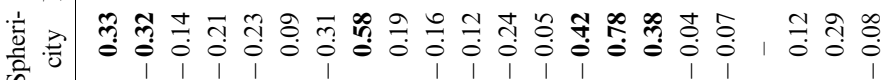

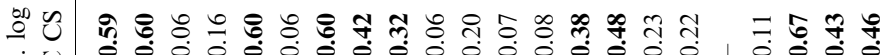

宇艺

1 1 1 1 ।

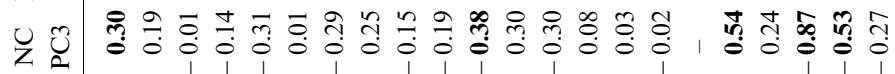

乙责

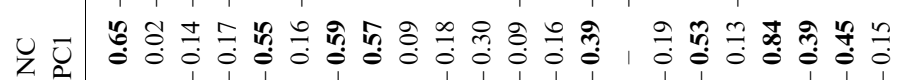

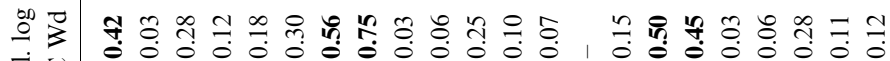

远

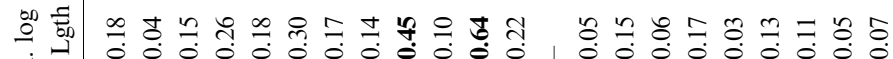

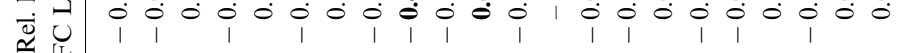

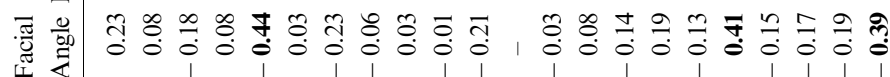

然

बं

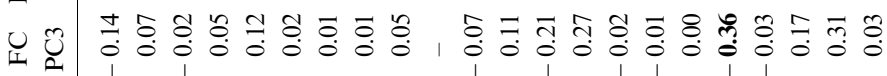

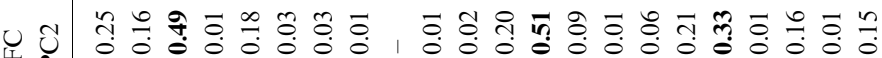

U

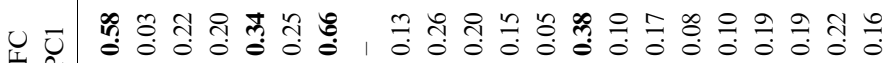

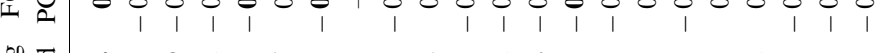

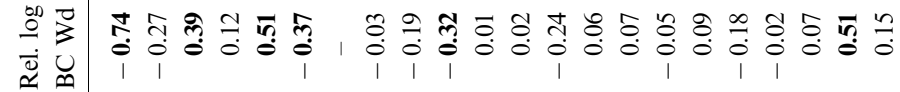

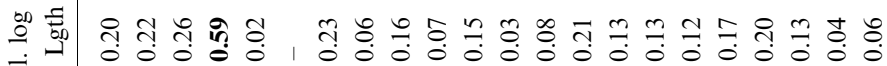

岕

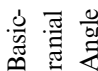

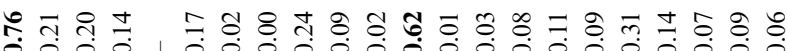

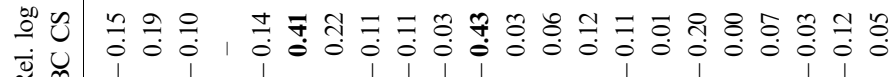

品

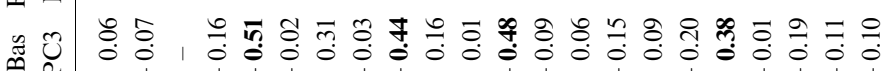

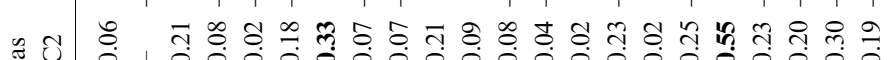

๓

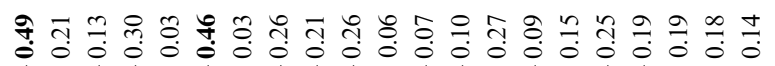

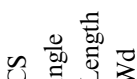

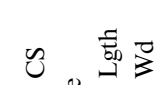

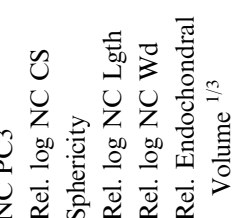


Copyright of Evolution \& Development is the property of Blackwell Publishing Limited and its content may not be copied or emailed to multiple sites or posted to a listserv without the copyright holder's express written permission. However, users may print, download, or email articles for individual use. 